\title{
A atuação do enfermeiro nos serviços de transplante de medula óssea
}

\author{
Viviane Sales Freire Silva*, Jéssica de Lyra Sousa**, Fátima Helena do Espírito Santo, D.Sc.***
}

*Enfermeira residente do Instituto Estadual de Hematologia Arthur de Siqueira Cavalcanti (HEMORIO) pela Universidade Federal do Estado do Rio de Janeiro (UNIRIO), **Enfermeira residente do Instituto Estadual de Hematologia Arthur de Siqueira Cavalcanti (HEMORIO) pela Universidade Federal do Estado do Rio de Janeiro (UNIRIO), Especialista em Vigilância Sanitária, ***Professora adjunto da Escola de Enfermagem Aurora de Afonso Costa da Universidade Federal Fluminense (EEAAC / UFF

\begin{abstract}
Resumo
Introdução: Este estudo tem como objetivos caracterizar a produção científica selecionada sobre as atividades do enfermeiro no serviço de transplante de medula óssea (TMO), identificar o que vem sendo publicado na literatura sobre o papel dos enfermeiros nesse serviço e discutir os limites e possibilidades de enfermeiros no TMO. Material e métodos: Trata-se de uma revisão integrativa descritiva exploratória e qualitativa. Para a seleção dos artigos utilizou-se as bases de dados da BVS, Bireme e Scielo. A busca foi realizada entre os meses de maio e outubro de 2010. Resultados: Das 102 referências, apenas 10 artigos foram selecionados para a amostra, desde os cuidados com o cateter, prevenção e tratamento da mucosite oral, o papel dos enfermeiros no hospital, comunicaçáo terapêutica, diagnósticos de enfermagem da NANDA, o que exige a atençáo maior de uma equipe multidisciplinar sobre um paciente submetido ao TMO. Conclusão: $\mathrm{O}$ enfermeiro em uma unidade de transplante de medula óssea abrange um vasto campo de ação, assumindo a responsabilidade pelo planejamento, implementaçáo, coordenação, monitoramento e avaliaçấo dos cuidados de enfermagem em todas as fases de tratamento.
\end{abstract}

Palavras-chave: cuidados de enfermagem, transplante de medula óssea, hematologia.

\section{Abstract \\ The role of nurses in bone marrow transplantation unit}

Introduction: This study aimed to characterize the selected publications related to nurse activities in bone marrow transplantation (BMT) unit, to identify what kind of literature has been published focusing on the role of nurses in BMT unit and to discuss the limits and possibilities of nurses in BMT. Methods: An integrative literature review with qualitative descriptive-exploratory method was used. Articles were selected using BVS databases, Bireme and Scielo. The search was performed from May to October 2010. Results: Ten out of 102 articles were selected for the sample, regarding the dressing covering the catheter, prevention and treatment of oral mucositis, the role of nurses in hospital, therapeutic communication, NANDA nursing diagnoses, and the importance of a multidisciplinary team attention to a patient in BMT unit. Conclusion: The nurse in a BMT unit covers a wide field of action, taking responsibility for the planning, execution, coordination, supervision and evaluation of nursing in all therapy phases.

Key-words: nursing care, bone marrow transplantation, hematology. 


\section{Resumen}

\section{El papel de los enfermeros en los servicios de trasplante de médula ósea}

Introducción: Este estudio tiene como objetivos caracterizar la producción científica seleccionada acerca de las actividades que los enfermeros desempeñan en el servicio de trasplante de médula ósea (TMO), identificar lo que la literatura ha publicado sobre el papel de los enfermeros en el servicio de TMO y discutir los límites y posibilidades de los enfermeros de TMO. Material y métodos: Se trata de una revisión integrativa descriptiva exploratoria y cualitativa. Se realizó la búsqueda para selección de los estudios en las bases de datos de BVS, Bireme e Scielo, entre los meses de mayo y octubre de 2010. Resultados: A partir de los 102 artículos, tan sólo 10 artículos fueron seleccionados para la muestra, referente al cuidado con el catéter, la prevención y el tratamiento de la mucositis oral, el papel del enfermero en el hospital, la comunicación terapéutica, los diagnósticos de enfermería NANDA, y lo que exige más atención del equipo multidisciplinario en paciente sometido a TMO. Conclusión: Los enfermeros en una unidad de TMO cubren un amplio campo de acción, asumiendo la responsabilidad de planificación, ejecución, coordinación, supervisión y evaluación de los cuidados de enfermería en todas las etapas del tratamiento.

Palabras-clave: cuidados de enfermería, el trasplante de médula ósea, hematología.

\section{Introdução}

O câncer é uma doença crônica que acomete as dimensôes física, psicológica, social e econômica da vida de um indivíduo. O diagnóstico de câncer pode se fazer acompanhar de uma tempestade emocional e alteraçóes no estilo de vida ou hábitos diários [1].

Os dados epidemiológicos mostram uma incidência significativa de câncer no Brasil. As estimativas para o ano de 2010 serão válidas também para o ano de 2011 e apontam para a ocorrência de 489.270 casos novos de câncer [2]. Dentre os cânceres com possibilidade e indicação de realização do Transplante de Medula Óssea (TMO), encontram-se as doenças onco-hematológicas (linfomas, leucemias, mielodisplasias), além de outras doenças que comprometem o funcionamento da medula óssea, como imunodeficiências, doenças genéticas hereditárias, alguns tumores sólidos e doenças autoimunes.

OTMO é um processo de substituição de uma medula óssea doente ou lesada por uma medula óssea com função normal. É um procedimento terapêutico que consiste na infusão, por via intravenosa, de sangue de medula óssea obtido de um doador, previamente selecionado, em um receptor adequadamente condicionado [3,4].

A atuação do enfermeiro nos serviços de TMO é de extrema importância e envolve muitas responsabilidades em vários aspectos. Isso, porque, além de prestar assistência direta e contínua aos clientes, oferecendo cuidados de forma global e especializa$\mathrm{da}$, atendendo sempre as suas necessidades e não deixando de lado a sua subjetividade, também deve oferecer suporte emocional aos familiares.
Assim, considerando a importância da enfermagem na assistência aos pacientes submetidos ao TMO, o presente trabalho tem como objetos caracterizar a produção científica selecionada acerca da atuaçáo do enfermeiro no serviço de TMO; identificar na literatura o que vem sendo divulgado sobre a atuação do enfermeiro no serviço de TMO; discutir os limites e possibilidades da atuação do enfermeiro no serviço de TMO.

Espera-se por meio deste estudo contribuir para a ampliaçáo de conhecimentos sobre a atuação do enfermeiro nos serviços de TMO, bem como a importância da sua participação em todas as etapas do processo já que este é um tema ainda pouco abordado na literatura.

\section{Material e métodos}

Trata-se de uma revisão integrativa que tem por finalidade reunir e sintetizar resultados de pesquisas sobre um determinado tema ou questão, de maneira sistemática e ordenada, contribuindo para o aprofundamento do conhecimento do tema investigado [5].

Para a seleção dos artigos utilizou-se as bases de dados da Biblioteca Virtual em Saúde (BVS), Bireme e Scielo. Para a busca dos artigos, os descritores utilizados foram: transplante de medula óssea; transplante de células tronco hematopoiéticas e Enfermagem; transplante de medula óssea e Enfermagem. Essa busca foi realizada entre os meses de maio e outubro de 2010.

De acordo com os objetivos da pesquisa, foram estabelecidos os critérios de inclusão: artigos que retratassem das açôes de enfermagem nos serviços 
de transplante de medula óssea, citando esse tipo de tratamento para as doenças oncohematológicas; artigos publicados em periódicos nacionais em língua portuguesa; artigos disponíveis na íntegra em versão online; artigos publicados no período de janeiro de 2000 a setembro de 2010. Por outro lado, os critérios de exclusão foram: artigos indisponíveis na íntegra em versão online; artigos publicados que não tivessem a Enfermagem como foco nos serviços de transplante de medula óssea.

\section{Referencial teórico}

\section{Transplante de Células Tronco Hematopoéticas (TCTH)}

De acordo com a Sociedade Brasileira de Transplante de Medula Óssea existem três tipos de transplante de medula óssea: autogênico, quando o doador e receptor são a mesma pessoa, ou seja, as células-tronco hematopoéticas são obtidas do próprio paciente e reinfundidas após o tratamento proposto; alogênico, quando o doador e receptor são pessoas diferentes, o doador deve ser compatível ao receptor, podendo ser consanguíneo (geralmente irmãos) ou náo (através de bancos de medula); e singênico, obtidas de um irmão gêmeo idêntico (homozigoto/univitelino), portanto, são perfeitamente compatíveis com o receptor ( são de incidência rara, com toxicidades e complicaçóes mínimas) [6].

Por ser um procedimento de alta complexidade para todos que o cercam, ou seja, para toda a equipe multiprofissional de saúde, o TMO é dividido em várias etapas as quais cada uma delas tem funçôes específicas e cuidados especializados.

Como todo tipo de transplante, é dividido em pré-transplante, o transplante propriamente dito e o pós-transplante. O pós-transplante, por sua vez, é subdividido em pós-imediato, pós- mediato e pós- tardio. Essas etapas possuem características bem distintas, pois cada uma realiza determinadas atribuiçôes. Além disso, essa divisão é feita de acordo com o número de dias de internação em que o cliente de encontra.

O processo de transplante de medula óssea pode ser representado pela Figura 1.

$\mathrm{O}$ primeiro contato do enfermeiro com o paciente ocorre no ambulatório, quando este é encaminhado com indicação para o transplante. Com a inclusáo do cliente no programa, é iniciado o protocolo de preparo que inclui as orientaçóes de admissão na unidade, seguindo-se a internação para o transplante propriamente dito. Após a recuperação hematopoética, ocorre a alta hospitalar planejada, e a continuação do tratamento será realizada no ambulatório [7].

\section{Resultados e discussão}

Foram encontrados 102 artigos, sendo que, somente 38 estavam em língua portuguesa. Dos 38 artigos em língua portuguesa foram pré-selecionados apenas 18 que estavam relacionados às ações de enfermagem nos serviços de transplante de medula óssea contemplando esse tipo de tratamento para as doenças oncohematológicas. A partir dos 18 artigos pré-selecionados, utilizou-se todos os critérios de inclusão e exclusão da pesquisa. Assim, obtivemos como amostra para compor esse estudo 10 referências como mostra a Tabela I.

A partir da análise dos artigos destacaram importantes reflexóes. Dentre os autores destaca-se maior produção de pesquisas relacionadas à temática por enfermeiros oncologistas.

É importante destacar como outros autores nutricionistas, fisioterapeutas, assistentes sociais e médicos oncologistas, que trabalhando de forma

Figura 1 - Etapas do transplante de medula óssea.

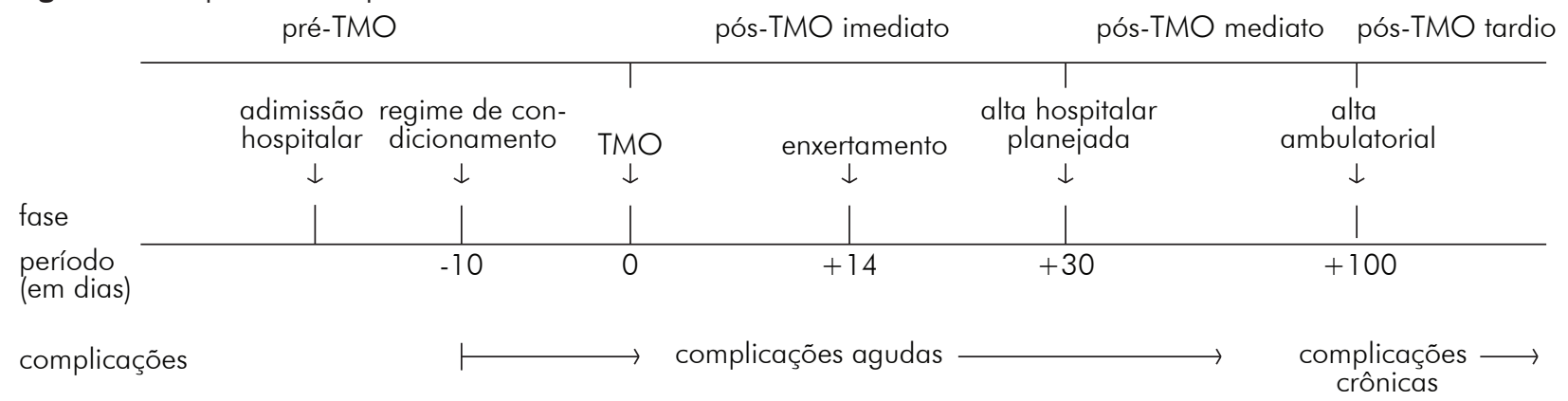

Fonte: [4]. 
Tabela I - Artigos selecionados de acordo com os critérios de inclusão e exclusão.

\begin{tabular}{|c|c|c|c|c|}
\hline Nome do artigo & Autores & Referência & Ano & Base de dados \\
\hline O cuidado de enfermagem e o cateter de & Silveira RCCP, & Acta Paul Enferm & 2005 & Lilacs e Scielo \\
\hline Hickman: a busca de evidências [8]. & Galvão CM & & & \\
\hline $\begin{array}{l}\text { Assistência de enfermagem em transplante } \\
\text { de células-tronco hematopoiéticas alogênico: } \\
\text { cuidados baseados em evidências [9]. }\end{array}$ & $\begin{array}{l}\text { Boschi KCG, Ka- } \\
\text { linke LP, Camar- } \\
\text { go JFC. }\end{array}$ & $\begin{array}{l}\text { Prática Hospi- } \\
\text { talar }\end{array}$ & 2007 & Google Acadêmico \\
\hline $\begin{array}{l}\text { Assistência de enfermagem no pós trans- } \\
\text { plante de medula óssea na leucemia linfóide } \\
\text { aguda na infância [10]. }\end{array}$ & $\begin{array}{l}\text { Aquino TP, Sanna } \\
\text { MC }\end{array}$ & Rev Paul Enferm & 2003 & Lilacs \\
\hline $\begin{array}{l}\text { Aspectos de enfermagem, nutrição, fisiotera- } \\
\text { pia e serviço social no transplante de medula } \\
\text { óssea [1 1] }\end{array}$ & Anders JC, et al. & $\begin{array}{l}\text { Medicina (Ribei- } \\
\text { rão Preto) }\end{array}$ & 2000 & Lilacs \\
\hline $\begin{array}{l}\text { Prevenção e tratamento da mucosite oral } \\
\text { [12]. }\end{array}$ & $\begin{array}{l}\text { Gondim FM, Go- } \\
\text { mes, IP, Firmino F }\end{array}$ & Rev Enferm UERJ & 2010 & Lilacs \\
\hline $\begin{array}{l}\text { Prática de liderança adotada por enfermeiros } \\
\text { no serviço noturno [13]. }\end{array}$ & $\begin{array}{l}\text { Moreira MC, } \\
\text { Silva SCSB }\end{array}$ & Rev Enferm UERJ & 2007 & Lilacs \\
\hline $\begin{array}{l}\text { Diagnóstico de enfermagem de pacientes } \\
\text { submetidos a transplante de medula óssea } \\
\text { alogênico: estudo de caso [14]. }\end{array}$ & $\begin{array}{l}\text { Magalhães AMM, } \\
\text { Matzenbacher } \\
\text { BCM, Pacheco } \\
\text { CRM }\end{array}$ & $\begin{array}{l}\text { Rev Gaucha } \\
\text { Enferm }\end{array}$ & 2005 & Lilacs \\
\hline $\begin{array}{l}\text { Breve reflexão sobre o autocuidado no plane- } \\
\text { jamento de alta hospitalar pós transplante de } \\
\text { medula óssea [15]. }\end{array}$ & Silva LMG da & $\begin{array}{l}\text { Rev Latinoam } \\
\text { Enferm }\end{array}$ & 2001 & Lilacs e Scielo \\
\hline $\begin{array}{l}\text { Demanda de atenção de um paciente na uni- } \\
\text { dade de transplante de medula óssea [16]. }\end{array}$ & $\begin{array}{l}\text { Pontes L, } \\
\text { Girardello EB, } \\
\text { Caudinei JG }\end{array}$ & $\begin{array}{l}\text { Rev Esc Enferm } \\
\text { USP }\end{array}$ & 2007 & Lilacs e Scielo \\
\hline $\begin{array}{l}\text { A comunicação terapêutica com pacientes } \\
\text { em Transplante de medula óssea: perfil do } \\
\text { comportamento verbal e efeito de estratégia } \\
\text { educativa [17]. }\end{array}$ & $\begin{array}{l}\text { Feminino } \mathrm{TZ} \\
\text { Carvalho EC }\end{array}$ & Cogitare Enferm & 2007 & Lilacs \\
\hline
\end{tabular}

conjunta com os enfermeiros nos setores de TMO, fazem com que a prestação de serviço seja de forma multiprofissional para o cliente.

Outro aspecto discutido foi em relação aos locais dos estudos em que foram realizadas as pesquisas. Observa-se um número maior de estudos realizados no Estado de Sáo Paulo. Isso se dá devido a maior concentraçáo de centros de TMO existentes no estado. Ao todo somam 24 centros entre hospitais e outras instituiçōes. Em segundo lugar, vem o Estado do Rio de Janeiro com 7 centros.

$\mathrm{O}$ ano de publicação dos artigos encontrados também é relevante de se analisar por se tratar de um tema recente na área científica. Nota-se que o ano de maior publicaçáo foi o de 2007 com quatro publicaçóes. Em seguida vem o ano de 2005 com duas publicaçóes e o restante dos anos apenas uma publicação. Isso demonstra a grande defasagem de publicaçóes acerca do tema discutido na literatura científica. Po- rém, também se pode observar o aumento gradual de publicaçóes com o decorrer do tempo. Isso se justifica pelo maior número de transplantes de medula óssea que vem sendo realizados em todo o país.

O Registro Nacional de Receptores de Medula Óssea (REREME) verificou um aumento considerável de realizaçóes de transplantes de medula óssea. Em 2007 foi confirmado estatisticamente como sendo o ano que mais se realizou esse tipo de transplante [18].

$\mathrm{O}$ ano de 2010 contradiz o dito anteriormente, porém é explicada pela pesquisa em questão realizada apenas até a metade desse ano o que não se pode confirmar sua baixa publicação.

Nota-se que a metodologia prevalente das publicaçóes é a de revisão de literatura e a de casos clínicos, com três referências cada. Em seguida, tem-se relato de experiência, revisáo sistemática, revisão integrativa e quase experimental, com apenas uma referência de cada. 
Prática assistencial de enfermagem em TMO

Silveira e Galvão [8] realizaram uma revisão integrativa na qual relatam os cuidados de enfermagem com o cateter de Hickman. Foi relatado maior satisfaçáo e conforto do paciente, além da redução dos custos com o material necessário. As diretrizes do CDC (Centro de controle e prevenção de doença) para o curativo de cateter tunelizado preconizam que o curativo de óstio pode ser, tanto com gaze estéril e esparadrapo quanto com películas de poliuretano, sendo preferível o curativo com gaze estéril em pacientes com sangramento e exsudação local abundante.

Boschi et al. [9] também abordam um pouco sobre esse tema, já que descreve toda a assistência de enfermagem em TCTH alogênico. Feminino e Carvalho [17] reforçam a necessidade de maiores cuidados de assepsia na manipulação destes cateteres. Produtos mais eficazes para a realização da antissepsia do cateter é a Clorexidina a 2\% e 83\% e, depois, a Clorexidina 0,5\% em 17\%.

Outros artigos [8,9] abordam os cuidados primordiais para a realização do curativo do CVC, sendo imprescindível a técnica asséptica em todo o processo. Além disso, vale destacar a grande importância do curativo permitir a visualização tanto do óstio de inserção do cateter quanto à região adjacente a ele.

Boschi et al. [9] também relata a mucosite oral em pacientes submetidos a TCTH alogênico. De acordo com os trabalhos pesquisados no artigo, a solução para mucosite de maior eficiência foi a Clorexidina $0,12 \%$, que deve ser utilizada antes do início do tratamento. Outro tema abordado foi sobre os alimentos para imunossuprimidos. Evidencia-se a necessidade de treinamentos frequentes aos colaboradores responsáveis pela manipulação dos alimentos, envolvendo cuidados de higiene pessoal e lavagem das mãos.

Revisão de literatura que abrange a Sistematização da Assistência de Enfermagem (SAE) na leucemia linfóide aguda na infância [10] considera que o enfermeiro exerce os papéis assistencial, administrativo, educativo e de pesquisa. Acredita-se que esta última tarefa é uma das mais importantes e, quando realizada com frequência e competência, tem reflexos positivos sobre as demais.

$\mathrm{O}$ artigo de Anders et al. [11] é uma revisão de literatura que abrange tanto as açóes de enfermagem nos TMO, como também da nutrição, fisioterapia e serviço social. Para a enfermagem serão tratados dois aspectos particulares da assistência de enfermagem ao TMO. O primeiro aspecto refere-se aos cuidados com o cateter venoso central. $\mathrm{O}$ segundo aspecto aborda os cuidados de enfermagem para o paciente com mucosite pós-TMO e as complicaçóes como sangramento, infecçáo, xerostomia e perda do paladar.

Gondim et al. [12] abordam a prevenção e tratamento da mucosite oral para identificar evidências sobre as açôes de enfermagem ao paciente com esse tipo de complicação no TMO.

\section{Planejamento de enfermagem em TMO}

O artigo de Moreira e Silva [13] discorre sobre a liderança dos enfermeiros no serviço noturno de um setor de hematologia clínica e transplante de medula óssea do Hospital Universitário Clemente Fraga Filho da Universidade Federal do Rio de Janeiro (HUCFG/UFRJ). Como modelo de liderança refere-se ao de Kouzer e Posner. Esse artigo foi o único encontrado relacionado com a parte gerencial da enfermagem nesses setores.

Estudo realizado [14] aborda os diagnósticos de enfermagem levantados por todos os enfermeiros da equipe de acordo com a NANDA. Tais diagnósticos referem-se a um paciente do sexo masculino com diagnóstico de linfoma de células T submetido ao TMO alogênico e que foram observados desde o dia -8 até o dia +31 . São eles: constipação, distúrbios de padrão de sono, hábitos de higiene inadequados, ansiedade por ambiente hospitalar, dor aguda, alteração na nutrição menos que o corpo necessita, alteração na mucosa oral, risco de infecçáo, excesso de líquidos, integridade tissular prejudicada, alteração na eliminação urinária. A partir desses diagnósticos estabelecidos, intervençóes foram realizadas e resultados foram alcançados. Os autores acreditam que a coleta de dados na fase de anamnese e exame físico são fundamentais para o julgamento clínico do enfermeiro na elaboração dos diagnósticos de enfermagem.

O estudo de caso realizado por Silva [15] trata de um paciente em fase de preparaçáo para a alta hospitalar pós-TMO, em um hospital de São Paulo. Reflete sobre o autocuidado no planejamento de alta hospitalar no pós-TMO. De acordo com a análise dos dados sugere que o paciente conheça as orientaçóes gerais, mas não detalha 
as açóes de autocuidado necessários para dar continuidade ao tratamento em casa, após a alta hospitalar. No entanto, algumas orientações merecem destaque tais como, a ingestâo de alimentos adequada com alimentos cozidos e descascados, fundamental para o processo de recuperaçáo. A ingestão hídrica também é importante e deve ser realizada de maneira adequada. Isso porque a ciclosporina, medicação utilizada para se obter imunossupressão necessária para evitar rejeiçóes do enxerto ou DECH (Doença do Enxerto Contra Hospedeiro) é nefrotóxica e, frequentemente, determina comprometimento renal.

$\mathrm{O}$ artigo de Gondim [12] também pode ser inserido nessa categoria de planejamento, já que contempla a prevençáo da mucosite oral em pacientes submetidos ao TMO e isso não deixa de ser uma forma de planejamento em enfermagem.

Nos artigos destacados é importante enfatizar a grande importância da educaçáo em saúde à qual os clientes em TMO devem ser submetidos. A equipe de enfermagem, principalmente o enfermeiro, tem como papel de nortear todas essas orientação para que todas as complicaçóes reais ou potenciais sejam tratadas devidamente tanto para o lado curativo quanto para o lado preventivo.

\section{Equipe e cliente em TMO}

Pontes e Claudinei [16] identificam as demandas de atenção vivenciadas por um paciente portador de leucemia mielóide aguda submetido à $\mathrm{TMO}$, seguindo o referencial teórico de atenção e demandas de atenção. Essas demandas foram categorizadas, de acordo com o paciente, e, posteriormente, divididas em domínios. O primeiro domínio mencionado foi o domínio afetivo em que a ausência da família foi a demanda que mais exigiu do paciente um esforço mental. Para isso a enfermeira pode oferecer um relacionamento interpessoal mais afetivo, minimizando a ausência da família. Já o domínio de informação inclui a imprecisáo e o excesso de informação. As informaçóes têm que ser claras e objetivas e talvez de forma mais coloquial e participativa. O domínio físico-ambiental inclui o espaço físico restrito, excesso de manuseio e interrupçáo do sono. Por fim, o domínio comportamental, que também foi relatado, está relacionado ao afastamento do trabalho.
A partir dos resultados obtidos julgou-se que o enfermeiro necessita conhecer as diferentes fontes de demanda de atenção a que esses pacientes estão expostos, uma vez que eles ocupam um papel essencial no processo de cuidar.

Feminino e Carvalho [17] descrevem a comunicação terapêutica com pacientes submetidos ao TMO. Os diálogos entre os profissionais de enfermagem e pacientes contemplam o emprego dos diferentes grupos de técnicas de comunicação, dividindo-as em terapêuticas e não terapêuticas. As mais utilizadas são as terapêuticas tais como: fazer perguntas e usar frases descritivas e técnicas de repetir a mensagem do paciente. As náo terapêuticas destacam: induzir respostas, mudar de assunto subitamente, além da falsa tranquilização.

Os artigos citados nesse eixo temático demonstram que atitudes simples dos profissionais de saúde (escuta ativa, atenção, conversa atenciosa, entre outros) com o cliente, durante a hospitalização, podem melhorar esse momento tão difícil e de grandes expectativas futuras.

\section{Discutindo os limites e possibilidades do enfermeiro no TMO}

A enfermagem atua diretamente no cuidado a esses clientes. Sua prática assistencial é muito ampla e deve ser realizada de maneira duplamente responsável e dedicada. Além disso, por se tratar de um procedimento terapêutico que é visto como última chance de cura da doença, o cliente, que já vem sendo submetido a outros métodos terapêuticos, porém sem sucesso, já se encontra totalmente frágil e debilitado tanto fisicamente quanto emocionalmente.

Como visto anteriormente, os artigos de 2000 a 2010 abordaram a forma de realização da troca do curativo no cateter totalmente implantado, a prevençáo e tratamento da mucosite oral, a importância do paciente ter uma boa alimentação e hidratação, educando-o e mostrando-lhe o que é melhor para equilibrar o seu quadro clínico. Em um comparativo com a pesquisa de realizada por Soler [19] sobre a produção científica da enfermagem em transplante de medula óssea no período de 1997 a 2007, podemos observar uma diferença de produção quanto ao aprofundamento científico do tema, correspondendo a situaçóes vivenciadas pelos pacientes e familiares submetidos ao TCTH; demandas de atenção ao paciente; aspectos psi- 
cossociais, dentre eles os estressores, sofrimento psíquico e comunicação terapêutica; organização e gerenciamento dos centros e serviços de TMO; cuidado, autocuidado, cuidado especializado, dentre eles, com os cateteres venosos centrais e assistência de enfermagem; diagnóstico de enfermagem; TCTH em crianças e adolescentes, trabalho multidisciplinar; qualidade de vida; e produção de conhecimento [19].

Devemos relatar também a importância de uma equipe multiprofissional na assistência a esses clientes submetidos ao TMO. O enfermeiro é o profissional essencial e mais atuante nesses serviços devido à enorme responsabilidade e as atividades que desenvolve junto ao cliente. Isso porque é o único profissional que permanece 24 horas por dia prestando assistência, além de ter a responsabilidade de cuidar de todo um setor e equipe que estáo diretamente ligados a sua recuperação. Porém, deve levar em consideração o trabalho em equipe nesses serviços.

\section{Conclusão}

Nota-se que de toda uma trajetória metodológica, começando com 314 referências relacionadas com o transplante de medula óssea como um todo, apenas 10 artigos foram selecionados para compor a amostra da pesquisa. Isso reforça a escassez de pesquisas e publicaçóes acerca da correlação do transplante de medula óssea e a enfermagem mencionada anteriormente, abrindo perspectivas para novos estudos que fortaleçam os conhecimentos sobre essa temática e favorecendo uma assistência de enfermagem mais adequada de melhor qualidade a esses clientes.

Assim, algumas limitaçóes podem ser levadas em consideração como poucas publicaçôes científicas acerca do tema o que dificulta a interação e a expansáo dos conhecimentos para os outros profissionais. Publicar artigos, principalmente de relato de experiência ou estudo de caso auxilia a todos saberem um pouco mais e compartilhar seus conhecimentos.

Entretanto, conseguiu-se compreender a atuação do enfermeiro nesses serviços. Podemos destacar: o tipo de abordagem que temos que ter com o paciente, o olhar global tanto na assistência como na gerência, o ambiente hospitalar, a realização dos curativos do cateter totalmente implantado, a prevenção de complicaçóes precoces e tardias, a educação em saúde na alta hospitalar, orientações aos familiares, a busca de métodos que melhorem a adaptação do cliente no hospital, dentre outras.

Algumas sugestóes devem ser levadas em consideração como a inclusão desse tipo de abordagem na grade curricular do Curso de Enfermagem, visto que é um tema de extrema relevância e de grande atuação para os enfermeiros.

\section{Referências}

1. Smeltzer SC, Bare BG. Tratado de Enfermagem Médico-Cirúrgica. 10a ed. Rio de Janeiro: Guanabara Koogan; 2006.

2. Brasil. Ministério da Saúde. Instituto Nacional de Câncer. Açóes de enfermagem para o controle do câncer: uma proposta de integraçáo ensino-serviço. $3^{\mathrm{a}}$ ed. Rio de Janeiro: INCA; 2008. 628p.

3. Otto SE. Oncologia. Rio de Janeiro: Reichmann e Affonso; 2002.

4. Riul S, Aguillar OM. Contribuição à organização de Serviços de transplante de medula óssea e a Atuação do enfermeiro. Rev Latinoam Enfermagem 1997;5(1)49-58.

5. Galvão CM, Sawada NO, Trevizan MA. Revisão Sistemática: recurso que proporciona a incorporação das evidências na prática da enfermagem. Rev Latinoam Enferm 2004 12(3):549-56.

6. Zanuto EI. Transplante de medula óssea: a versão de quem fez. São Paulo: Pancast; 1997. 116 p.

7. Lacerda MR, Lima JBG, Barbosa R. Prática de enfermagem em transplante de células tronco hematopoiéticas. Rev Eletrônica Enferm 2007;09(01):242-50.

8. Silveira RCCP, Galvão CM. O cuidado de enfermagem e o cateter de Hickman: a busca de evidências. Acta Paul Enferm 2005;18(3):276-84.

9. Boschi KCG, Kalinke LP, Camargo JFC. Assistência de Enfermagem em transplante de células-tronco hematopoiéticas alogênico: Cuidados baseados em evidências. Prát Hosp 2007;9(49):31-7.

10. Aquino TP, Sanna MC. Assistência de enfermagem no pós transplante de medula óssea na Leucemia Linfóide Aguda na infância. Rev Paul Enferm 2003;22(1):100-7.

11. Anders JC, Soler VM, Brandão EM, Edith M, Vendramini EC, Bertagnolli C, et al. Aspectos de enfermagem, nutrição, fisioterapia e serviço social no transplante de medula óssea. Medicina (Ribeirão Preto) 2000;33(4):463-85.

12. Godim FM, Gomes IP, Firmino F. Prevenção e tratamento da mucosite oral. Rev Enferm UERJ 2010;18(1):67-74.

13. Moreira MC, Silva SCSB. Prática de liderança adotada por enfermeiros no serviço noturno. Rev Enferm UERJ 2007;15(2):183-9. 
14. Magalhães AMM, Matzenbacher BCM, Pacheco CRM. Diagnóstico de enfermagem em pacientes submetidos a transplante de medula óssea alogênico: estudo de caso. Rev Gaucha de Enferm 2005;26(1):67-75.

15. Silva LMG. Breve reflexão sobre o autocuidado no planejamento de alta hospitalar pós transplante de medula óssea. Rev Latinoam Enferm 2001;9(4):7582.

16. Pontes L, Guirardello EB, Claudinei JG. Demanda de atençáo de um paciente na unidade de transplante de medula óssea. Rev Esc Enferm USP 2007;41(1):154-60.
17. Feminino TZ, Carvalho EC. A comunicação terapêutica com pacientes em transplante de medula óssea: perfil do comportamento verbal e efeito de estratégia educativa. Cogitare Enferm 2007;12(3):287-95.

18. AMEO - Associação de Medula Óssea. Doação de medula. [citado em 17/10/2010]. Disponível em URL: http://www.abto.org.br

19. Soler VM. O conhecimento produzido pela enfermagem em transplante de medula óssea no Brasil [Tese]. Escola de Enfermagem de Ribeirão Preto da Universidade de São Paulo; 2006. 